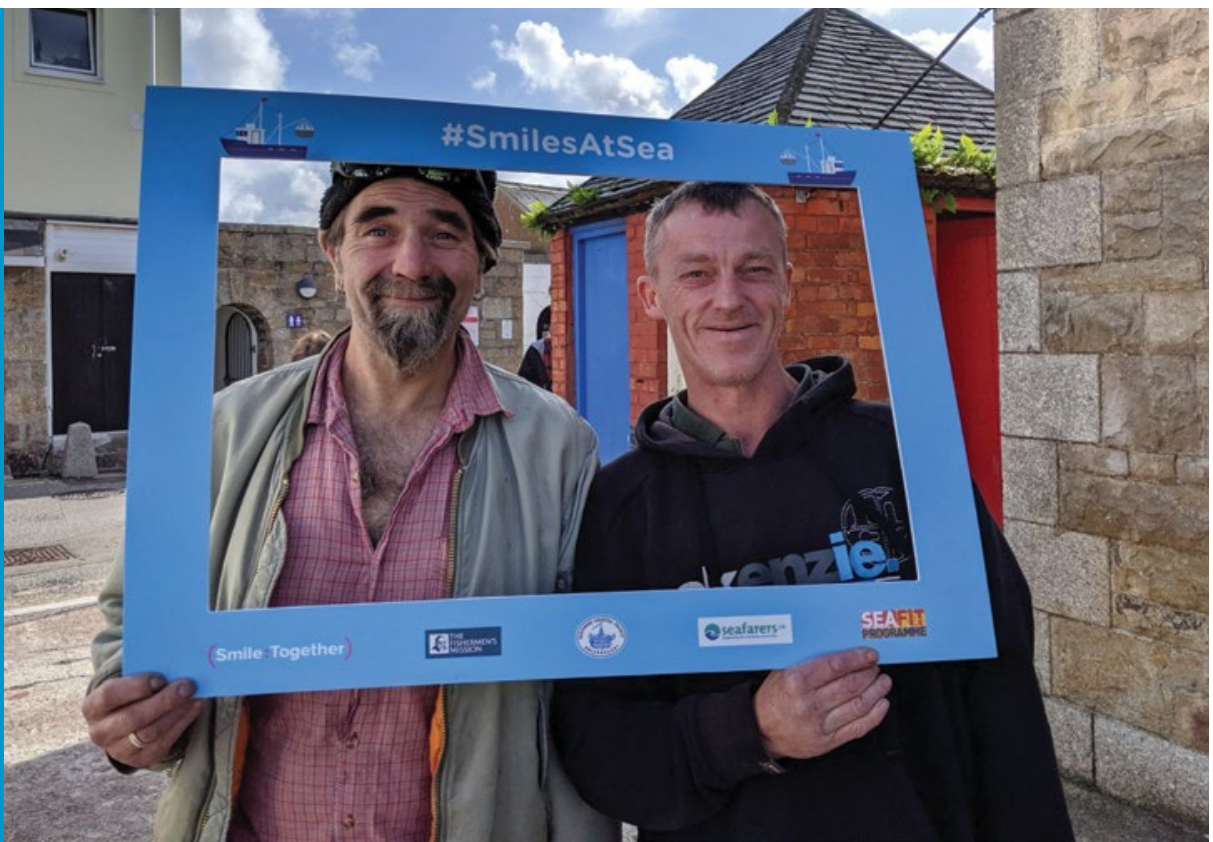

\title{
SEAFIT AND SMILESATSEA SHORTLISTED FOR PRESTIGIOUS AWARD
}

The SeaFit and SmilesAtSea partnership has been shortlisted in the Third Sector Charity Business Awards as Project of the Year. This prestigious charity award recognises outstanding partnerships between UK businesses and good causes. SmilesAtSea, initiated by Smile Together Dental CIC, is a partner of the SeaFit Programme. Together they have been offering free dental checkups and emergency treatment to fishing communities from a mobile dental unit located on or near harboursides in Cornwall and Devon.

The SmilesAtSea tour was started by Smile Together in 2017, gained funding from the Seafarers Hospital Society in 2018 and was then adopted and expanded by the UK wide SeaFit Programme. Last year's tour was the most successful yet, covering nine fishing ports in three weeks and treating 173 members of the fishing community.

Speaking about the awards, SeaFit Project Delivery Manager Carol Elliott said: 'We're delighted to have been shortlisted in recognition of the invaluable support we are providing to fishermen. Sadly there won't be an awards ceremony this year because of the Coronavirus but it doesn't detract from the excitement for us and our partners'.

In the short-term COVID-19 has put a stop to upcoming SeaFit events, but it is hoped that SmilesAtSea 2020 will be late enough in the year to go ahead. 'Our next tour has been provisionally planned for September and we are hoping we will once again be able to support fishermen on the quaysides,' said Carol.
GDC RESPOND TO CRISIS

In response to the COVID-19 pandemic, the General Dental Council (GDC) says that it will look sympathetically at the circumstances of any registrant who has a shortfall in their continuing professional development (CPD) declaration this year. The regulator has stated that nobody will be removed from the register because of a lack of access to CPD during the crisis period. For queries or concerns please email cenquiries@ gdc-uk.org.

Thousands of students will have been due to complete their professional training over the coming months and then to register with the GDC. Teaching and assessment are being severely disrupted, but the GDC has been working with education providers to ensure that as many students as possible can still have a smooth transition into practice. A statement has been published on the GDC website and includes relevant contact details: https:// bit.ly/2QT8lqA.

Many will have seen the appeals to doctors, nurses and other healthcare professionals whose registration has lapsed to return to work, and the GDC has been asked whether similar arrangements will be made for dental professionals. As things currently stand, the only legal route back onto the register is by individual restoration: https://bit. ly/2Jn1qBR.

Almost all fitness to practise hearings have been postponed. The GDC aims to run urgent hearings remotely whenever possible. It will look to relist postponed hearings when safe and appropriate.

\section{SDCEP COVID-19 guidance update}

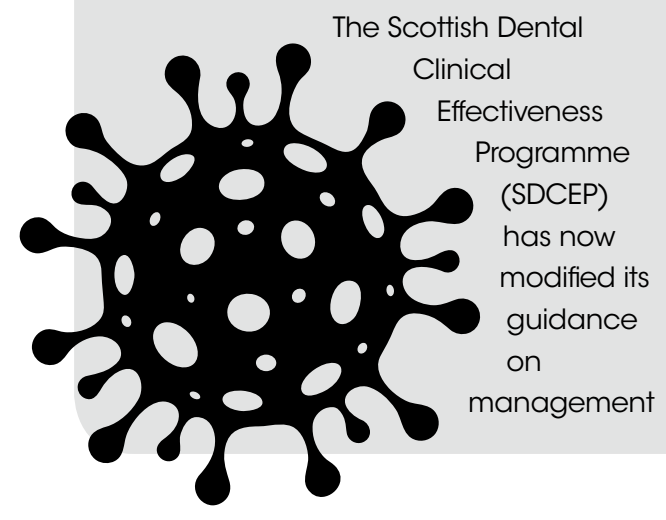

of commonly presenting oral conditions for use during the COVID-19 pandemic. The new Management of Acute Dental Problems during COVID-19 Pandemic guide is available now on the SDCEP website: http://www.sdcep.org.uk/ published-guidance/acute-dentalproblems-covid-19/.

This guide is for use by dental teams involved in triaging and managing patients during the current situation. It can be used in conjunction with health board or other local procedures that have been established for managing patients based on their COVID-19 status.

Note that this guide is subject to change as new information becomes available. Therefore, please ensure that you are viewing the most recent version by referring to: www.sdcep.org.uk. 